REFERENCES

[1] Husni ME, et al. Presented at EULAR 2018, Amsterdam, the Netherlands.

Disclosure of Interests: Atul Deodhar Grant/research support from: AbbVie, Amgen, Eli Lilly, GSK, Janssen, Novartis, Pfizer, and UCB, Consultant for: AbbVie, Amgen, BMS, Eli Lilly, Janssen, Novartis, Pfizer, and UCB, M Elaine Husni Grant/research support from: Janssen, Sergio Schwartzman Shareholder of: Amgen, Boston Scientific, Gilead, Medtronic, and Pfizer, Consultant for: AbbVie, Crescendo, Dermtech, Janssen, Gilead, Lilly, Myriad, Novartis, Regeneron, Samsung, Sanofi, and Union Chimique Belge, Speakers bureau: Abbott/AbbVie, Genentech, Janssen, Lilly, Novartis, Pfizer, Regeneron, Sanofi, and Union Chimique Belge, Shelly Kafka Shareholder of: J\&J, Employee of: J\&J, Soumya D Chakravarty Shareholder of: Johnson \& Johnson, Employee of: Johnson \& Johnson, Elizabeth C Hsia Employee of: Employee of Janssen Research \& Development, LLC, Diane D Harrison Employee of: Janssen Research \& Development, LLC, Jocelyn H Leu Employee of: Janssen Research \& Development, LLC, Yiying Zhou Employee of: Janssen Research \& Development, LLC, Kim Hung Lo Employee of: Janssen Research \& Development, LLC, Arthur Kavanaugh Grant/research support from: UCB Pharma DOI: 10.1136/annrheumdis-2019-eular.179

\section{AB0386 RESPONSE TO BIOLOGIC THERAPY IS INFLUENCED BY THE BODY MASS INDEX IN PATIENTS WITH RHEUMATOID ARTHRITIS}

Hitoshi Kodera ${ }^{1}$, Yoshiko Sato ${ }^{2}$, Yoshifuji Matsumoto ${ }^{1} .{ }^{1}$ Kuwana city medical center, Kuwana, Japan; ${ }^{2}$ Yokkaichi Hazu medical center, Yokkaichi, Japan

Background: Biologic therapies have been bringing huge advantage in the treatment of rheumatoid arthritis, but response to the therapy is heterogeneous. The influence of the body mass index to the treatment is still controversial.

Objectives: To identify the factors influencing in the response to biologic therapy (bio naïve).

Methods: The analysis of the patients with rheumatoid arthritis who were initiated biologics therapy (bio naïve) between January 2011 to December 2016 in the rheumatology department of a hospital in Japan, was conducted. The effects were evaluated by EULAR response criteria after 6 months of biologic therapy, and factors influencing the response were analyzed in terms of the baseline characteristics (sex, age, disease duration, body mass index, tender joint count, swollen joint count, Patient's visual analog scale, Doctor's visual analog scale, erythrocyte sedimentation rate, C-reactive protein, Disease Activity Score in 28 joints, Modified Health Assessment Questionnaire, Methotrexate use, Prednisolone use).

Table 1

Table 1. Difference of the baseline characteristics of RA patients between "Good or Moderate response" and "No response" of EULAR response criteria after 6 months of biologic therapy.

\begin{tabular}{|c|c|c|c|}
\hline & $\begin{array}{l}\text { Good or Moderate response } \\
(n=82)\end{array}$ & $\begin{array}{l}\text { No response } \\
(\mathrm{n}=63)\end{array}$ & $\mathrm{p}$-value \\
\hline Female sex, no. $(\%)$ & $69(84.1 \%)$ & $53(84.1 \%)$ & 0.9975 \\
\hline Age, years & $55.4 \pm 15.6$ & $59.2 \pm 12.9$ & 0.1115 \\
\hline Disease duration, years & $6.6 \pm 3.6$ & $7.8 \pm 3.9$ & 0.0477 \\
\hline BMI, $\mathrm{kg} / \mathrm{m}^{2}$ & $22.0 \pm 3.4$ & $24.4 \pm 5.2$ & 0.0008 \\
\hline$\geq 25$, no. $(\%)$ & $12(14.6 \%)$ & $22(35 \%)$ & 0.0043 \\
\hline TJC & $5.6 \pm 6.1$ & $4.0 \pm 5.4$ & 0.0972 \\
\hline SJC & $3.4 \pm 4.8$ & $1.5 \pm 2.4$ & 0.0018 \\
\hline Patient's VAS (range 0-100) & $46.6 \pm 24.6$ & $34.4 \pm 27.4$ & 0.0052 \\
\hline Doctor's VAS (range 0-100) & $44.6 \pm 25.8$ & $34.3 \pm 28.0$ & 0.0223 \\
\hline ESR mm/hour & $62.8 \pm 34.2$ & $59.0 \pm 31.8$ & 0.5702 \\
\hline $\mathrm{CRP} \mathrm{mg} / \mathrm{dL}$ & $1.7 \pm 2.1$ & $0.9 \pm 1.7$ & 0.0094 \\
\hline DAS28-ESR & $4.9 \pm 1.2$ & $4.2 \pm 1.3$ & 0.0015 \\
\hline DAS28-CRP & $3.9 \pm 1.2$ & $3.1 \pm 1.3$ & $<.0001$ \\
\hline mHAQ & $0.5 \pm 0.5$ & $0.5 \pm 0.6$ & 0.3829 \\
\hline \multicolumn{4}{|l|}{ Concomitant therapy } \\
\hline MTX, no. (\%) & $62(75.6 \%)$ & $47(74.6 \%)$ & 0.8894 \\
\hline MTX dose, mg/week & $7.4 \pm 4.6$ & $7.8 \pm 5.0$ & 0.7134 \\
\hline Steroid, no. (\%) & $46(56.1 \%)$ & $48(76.2 \%)$ & 0.0120 \\
\hline Prednisolone dose, mg/day & $1.6 \pm 2.3$ & $3.9 \pm 8.8$ & 0.5156 \\
\hline
\end{tabular}

Table 2.

Table 2. Logistic regression analysis of "Good or Moderate response" of EULAR response criteria Table 2. Logistic regression analysis of "Good or Moderate response" of EULAR response criteria
after 6 months of biologic therapy by baseline body mass index among Tumor Necrosis Factor users, IL-6-receptor inhibitor users and CTLA4-Ig users.

\begin{tabular}{lccc}
\hline Biologics & Odds Ratio & $95 \%$ confidence interval & $\mathrm{p}$-value \\
\hline TNF inhibitor & 0.88 & $0.78-0.99$ & 0.0428 \\
IL-6 receptor inhibitor & 0.75 & $0.61-0.93$ & 0.0093 \\
CTLA4-Ig & 0.95 & $0.79-1.13$ & 0.5757
\end{tabular}

Results: There were differences of baseline characteristics in disease duration and body mass index between the patients who achieved "Good or Moderate response" and "No response" of EULAR response criteria after 6 months of biologic therapy (table 1). The latter was more significant, and the difference was found among biologics (table 2).

Conclusion: Body mass index influence in the response to first biologic therapy in patients with rheumatoid arthritis.

Disclosure of Interests: None declared

DOI: 10.1136/annrheumdis-2019-eular.5170

\section{AB0387 SATISFACTION OF PATIENTS AND PHYSICIANS WITH TREATMENTS FOR RHEUMATOID ARTHRITIS: A NATIONWIDE SURVEY IN CHINA}

Nan Jiang ${ }^{1}$, Pingting Yang ${ }^{2}$, Shengyun $\mathrm{Liu}^{3}$, LI Hongbin ${ }^{4}$, Lijun Wu ${ }^{5}$, Xiaofei Shi ${ }^{6}$, Yongfei Fang ${ }^{7}$, Yi Zhao ${ }^{8}$, Jian $\mathrm{Xu}^{9}$, Zhenyu Jiang ${ }^{10}$, Zhenbiao Wu ${ }^{11}$, Xingwang Duan ${ }^{12}$, Qian Wang ${ }^{1}$, Xinping Tian ${ }^{1}$, Mengtao Li ${ }^{1}$, Xiaofeng Zeng ${ }^{1}$. ${ }^{1}$ Department of Rheumatology, Peking Union Medical College Hospital, Beijing, China; ${ }^{2}$ Department of Rheumatology and Immunology, First Affiliated Hospital, China Medical University, Shenyang, China: ${ }^{3}$ Department of Rheumatology, the First Affiliated Hospital of Zhengzhou University, Zhengzhou, China; ${ }^{4}$ Department of Rheumatology, Affiliated Hospital of Inner Mongolia Medical College, Hohhot, China; ${ }^{5}$ Department of Rheumatology and Immunology, People's Hospital of Xinjiang Uygur Autonomous Region, Urumqi, China; ${ }^{6}$ Department of Rheumatology and Immunology, the First Affiliated Hospital, and College of Clinical Medicine of Henan University of Science and Technology, Luoyang, China; ${ }^{7}$ Department of Rheumatology, Southwest Hospital, Third Military Medical University, chongqing, China; ${ }^{8}$ Department of Rheumatology and Immunology, West China Hospital, Sichuan University, Chengdu, China; ${ }^{9}$ Department of Rheumatology and Immunology, First Affiliated Hospital of Kunming Medical University, Kunming, China; ${ }^{10}$ Department of Rheumatology, the First Hospital of Jilin University, Changchun, China; ${ }^{11}$ Department of Clinical Immunology and Rheumatology, Xijing Hospital affiliated to the Fourth Military Medical University, Xi'an, China; ${ }^{12}$ Department of Rheumatology, The Second Affiliated Hospital of Nanchang University, Nanchang, China

Background: Treatment satisfaction is important for adherence to therapy both for patients and physicians. There is no full understanding of the treatment satisfaction for rheumatoid arthritis (RA) in China.

Objectives: The aim is to explore the treatment satisfaction between rheumatologists and RA patients across China and the factors associated with patients' satisfaction.

Table 1.

\begin{tabular}{|c|c|c|c|c|}
\hline Treatment & & Patients & Physicians & $P$ \\
\hline All medications for & & & & \\
\hline $\begin{array}{l}\text { patients/ csDMARDs for } \\
\text { physicians }\end{array}$ & $N$ & 1237 & 146 & \\
\hline Effectiveness & Median (range) & $83.3(0-100)$ & $66.7(33.3-100)$ & \\
\hline Side effects & Median (range) & $\begin{array}{l}100 \quad(16.7- \\
100)\end{array}$ & $75(16.7-100)$ & \\
\hline Convenience & Median (range) & $\begin{array}{l}81.3 \quad(18.6- \\
100)\end{array}$ & $68.8(31.3-100)$ & \\
\hline Global satisfaction & Median (range) & $\begin{array}{l}83.3 \quad(8.3- \\
100)\end{array}$ & $66.7(16.7-100)$ & \\
\hline bDMARDs & $N$ & 335 & 146 & \\
\hline Effectiveness & Median (range) & $83.3(0-100)$ & $75(33.3-100)^{*}$ & 0.302 \\
\hline Side effects & Median (range) & $100(8.3-100)$ & $\begin{array}{l}87.5 \quad(16.7- \\
100)^{*}\end{array}$ & $<0.001$ \\
\hline Convenience & Median (range) & $75(0-100)$ & $68.8(12.5-100)$ & 0.001 \\
\hline Global satisfaction & Median (range) & $75(0-100)$ & $75(16.7-100)^{*}$ & 0.889 \\
\hline
\end{tabular}




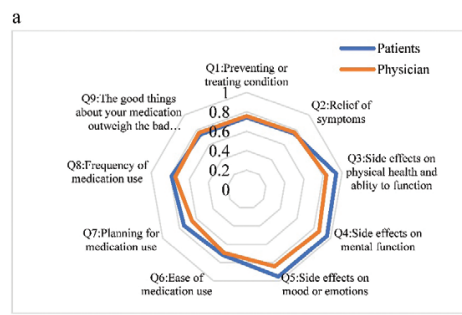

b

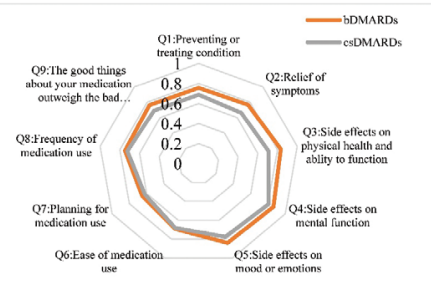

Figure 1 Radar charts with each item for the satisfaction between patients and physicians.

Methods: We conducted a prospective, multicenter, observational study of physicians and patients in 12 centers from 11 provinces across China between March and April 2018 (NCT03483597). The Treatment Satisfaction Questionnaire for Medication version II (TSQM-II) was used to assess the treatment satisfaction of patients and physicians regarding to csDMARDs and bDMARDs therapy. Multiple linear regression analysis was used to determine the factors independently associated with patients' satisfaction.

Results: 1237 patients (82.5\% female) with a mean age (SD) of 48.9 (13.4) years and 146 rheumatologists (72.6\% working $>5$ years) were included in this survey. The patients' satisfaction $(n=335)$ with bDMARDs was higher than physicians' satisfaction $(n=146)$ regarding the side effects (95.0 \pm 14.3 vs. $84.6 \pm 15.7, p<0.001)$ and convenience $(74.6 \pm 21.2$ vs. 69.1 $\pm 16.5, \quad p=0.002$ ) (Table1). Among physicians, global satisfaction with bDMARDs was higher than that with csDMARDs (75.0 vs. 66.7, $\mathrm{p}<0.05$ ) (Table1). Satisfaction of each questionnaire item toward therapy in patients and rheumatologists were also shown in radar charts (Figure 1). The multivariable regression analysis showed that age and quality of communication with physician was positively associated with patients' satisfaction, while level of education (bachelor or above), self-assessment of disease severity and treatment costs were inversely associated with satisfaction.

Conclusion: For bDMARDs, the treatment satisfaction of patients with RA is generally better than that of physicians. Physicians' satisfaction with bDMARDs is higher than that with csDMARDs. The independently factors associated with the treatment satisfaction of patients with RA are age, education, disease severity, the patient-physician communication, and treatment costs, which could be targeted in routine clinical care.

\section{REFERENCES}

None

Acknowledgement: The authors acknowledge contributions from the HealthCloud Co., Ltd as the system provider.

Disclosure of Interests: None declared

DOI: 10.1136/annrheumdis-2019-eular.3154

\section{AB0388 COMPARATIVE EFFECTIVENESS OF RITUXIMAB, TOCILIZUMAB AND TNFI BIOLOGICS IN RHEUMATOID ARTHRITIS PATIENTS. INFLUENCE OF CLINICAL AND INFLAMMATORY PROFILES}

Chary Lopez-Pedrera ${ }^{1}$, Nuria Barbarroja Puerto ${ }^{1}$, Carlos Perez-Sanchez ${ }^{1}$, Alejandro Ibañez-Costa ${ }^{1}$, Maria Luque-Tevar ${ }^{1}$, Alejandra Patiño-Trives ${ }^{1}$, Iván Arias de la Rosa ${ }^{1}$, Maria del Carmen Abalos-Aguilera ${ }^{1}$, Rafaela Ortega Castro ${ }^{1}$, Alejandro Escudero Contreras ${ }^{1}$, Pérez Sánchez Laura ${ }^{1}$, Carlos RodríguezEscalera $^{2}$, Dolores Ruiz-Montesinos ${ }^{3}$, Carmen María Romero-Barco ${ }^{4}$, Natalia Mena-Vázquez $z^{5}$, Julia Uceda ${ }^{6}, M^{2}$ Dolores Toledo-Coello ${ }^{7}, M^{2}$ Ángeles Aguirre-Zamorano ${ }^{1}$, Eduardo Collantes Estevez ${ }^{1} .{ }^{1}$ IMIBIC/Reina Sofia Hospital/ University of Cordoba, Cordoba, Spain; ${ }^{2} \mathrm{Hospital}$ de Jaen, Jaen, Spain; ${ }^{3}$ Hospital Virgen de la Macarena, Sevilla, Spain; ${ }^{4}$ IBIMA/Hospital de Torremolinos, Malaga, Spain; ${ }^{5}$ IBIMA/Hospital Regional Universitario, Malaga, Spain; ${ }^{6}$ Hospital Virgen de Valme, Sevilla, Spain; ${ }^{7}$ Hospital de Jerez, Cadiz, Spain

Objectives: 1) To compare the real-world effectiveness among RA patients starting 3 biologic DMARDs (bDMARDs). 2) To evaluate whether patients' clinical characteristics influence the response to specific bDMARDs. 3) To analyze the impact of bDMARDs on inflammatory profiles.

Methods: Eighty RA patients initiating TNFi, 22 patients treated with TCZ and 28 treated with RTX, the last ones after switching from TNFi and given as second bDMARDs, were included in the study. Effectiveness was assessed before and after 3 and 6 months of treatment by the European League Against Rheumatism (EULAR) criteria. Adjusted differences were estimated with multivariable linear regression. Differences in treatment outcomes were calculated as a function of patients' characteristics, through regression modelling. Extensive analysis of the inflammatory profile using a multiplex were also performed.

Results: A high proportion of patients starting TNFi showed early EULAR Good Response (65,8\% responders at 3 months). After 6 months of therapy this percentage even increased $(70,6 \%)$, so that tender joints' counts, swollen joints count, SDAI and HAQ improved significantly.

After switching from a first TNFi, RTX treatment promoted better early response ( $81,8 \%$ responders after 3 months) than TCZ (67\% responders). Differences remained significant after adjusting for potential confounders. Yet, after 6 months, efficacy was similar among both non-TNFi DMARDs, even improving the effectiveness in TCZ-treated RA patients based on EULAR response rate (DAS28 change: $5.09 \pm 1.4$ to $2.7 \pm 1,17$ ) vs RTXtreated patients (DAS28 change: $4.8 \pm 1.3$ to $3-1 \pm 1.3$ ).

Patients older, and those suffering arterial hypertension (AH) or hyperlipidemia showed less effectiveness for both, TNFi and non-TNFi DMARDs, most remarkable for RTX and after 6 months of treatment.

Analysis of the inflammatory profile, by evaluating 27 key biomarkers of inflammation, showed, in patients' responders to therapy, specific profiles depending on the biologic DMARD administered. Thus, after 6 months of RTX, a generalized reduction in the expression levels of 22/27 proteins evaluated was observed, while TCZ mainly inhibited proteins involved in cell maturation, proliferation and leukocytes recruitment (IL6, GCSF, IP-10, IFN $\gamma$, RANTES). On the other hand, TNFi mainly reduced molecules related to leukocytes' recruitment (IL-2, IL-8, MIP1 $\beta$, RANTES).

Conclusion: 1) Treatment outcomes among RA patients treated with nonTNFi bDMARDs in standard clinical practice, are in line with a superior early effectiveness of RTX compared with TCZ. However, effectiveness in TCZ-treated RA patients increases after 6 months of treatment vs RTX. 2) Patients characteristics influence the response to bDMARDs, suggesting the need of evaluating the benefit risk/ratio based on a personalized clinical evaluation. 3) Anti-inflammatory benefits associated with bDMARDs treatments can differ despite similar drug efficacy against RA, indicating that drug-specific mechanisms are involved in regulating these processes. Acknowledgement: Funded by PI-0285-2017, ISCIII, PI15/00837 and RIER RD16/0012/0015, co-funded with FEDER

Disclosure of Interests: Chary Lopez-Pedrera: None declared, Nuria Barbarroja Puerto: None declared, Carlos Perez-Sanchez: None declared, Alejandro Ibañez-Costa: None declared, Maria Luque-Tevar: None declared, Alejandra Patiño-Trives: None declared, Iván Arias de la Rosa: None declared, Maria del Carmen Abalos-Aguilera: None declared, Rafaela Ortega Castro: None declared, Alejandro Escudero Contreras: None declared, Pérez Sánchez Laura: None declared, Carlos RodríguezEscalera: None declared, Dolores Ruiz-Montesinos: None declared, Carmen María Romero-Barco: None declared, Natalia Mena-Vázquez: None declared, Julia Uceda Speakers bureau: abbie, pfizer, novartis, janmsen, Ma Dolores Toledo-Coello: None declared, M Ángeles Aguirre-Zamorano: None declared, Eduardo Collantes Estevez: None declared DOI: 10.1136/annrheumdis-2019-eular.7072

\section{AB0389 BIOSIMILAR ETANERCEPT VERSUS ORIGINATOR: RESULTS FROM A LONGITUDINAL PROSPECTIVE MONOCENTRIC STUDY}

Ramona Lucchetti, Fulvia Ceccarelli, Carlo Perricone, Simona Truglia,

Francesca Miranda, Manuela DI Franco, Valeria Riccieri, Rossana Scrivo, Antonio Sili Scavalli, Francesca Spinelli, Cristiano Alessandri, Guido Valesini,

Roberta Priori, Fabrizio Conti. Policlinico Umberto I, Sapienza University of Rome, Rheumatology, Department of Internal Medicine and Medical Specialities, Rome, Italy

Background: The introduction of TNF inhibitors have revolutionized the outcome of patients affected by Rheumatoid Arthritis (RA). In the last years, pharmaco-economic implications determined the introduction of biosimilar as alternative to originator biological drugs. Phase I and head-tohead phase III clinical studies demonstrated pharmacokinetic equivalence and comparability in terms of efficacy, safety, immunogenicity and tolerability. However, biosimilar drugs demonstrated some differences related to charge and glycosylation, not influencing the function and the ability to 